\title{
THE RELATIONSHIPS OF OXYGEN, CARBON DIOXIDE, AND HEMOGLOBIN IN THE BLOOD OF MAN : OXYHEMOGLOBIN DISSOCIATION UNDER VARIOUS PHYSIOLOGICAL CONDITIONS ${ }^{1}$
}

\author{
By R. L. RILEY,2 J. L. LILIENTHAL, JR.,2 D. D. PROEMMEL,? AND R. E. FRANKE * \\ (From the Naval School of Aviation Medicine, U. S. Naval Air Training Bases, \\ Pensacola, Florida)
}

(Received for publication October 3, 1945)

The wide variations in the oxyhemoglobin dissociation curves defined by early investigators were found subsequently to be the result of a variety of uncontrolled factors, such as the source and state of the hemoglobin, the $\mathrm{CO}_{2}$ pressure and $\mathrm{pH}$, the salt concentration, and the temperature $(2 \mathrm{~b}, 4)$. When these factors were controlled, the oxyhemoglobin dissociation curve was found to be constant for a given set of conditions, and standard curves were determined for whole blood at a given $\mathrm{pHs}$ at $37^{\circ} \mathrm{C}$. (4). These determinations were all made in vitro ${ }^{5}$ owing in part to a lack of any suitable technic for estimating directly the blood gas tensions in blood as drawn. A method for the direct determination of $\mathrm{pO}_{2}$ of blood was introduced (3), but so far as we are aware the only application of the direct method to the definition of the oxyhemoglobin dissociation

1 The opinions or assertions contained herein are the private ones of the writers and are not to be construed as official or reflecting the views of the Navy Department or the naval service at large.

2 Lieutenant, (M.C.), USNR.

8 PhM 1/c, W.A.V.E.S., USNR.

S 1/c, W.A.V.E.S., USNR.

The following connotations have been assigned to the terms used in this paper:

in vitro oxyhemoglobin dissociation refers to the relationships between oxygen tension and oxygen saturation which exist after equilibration of blood in a tonometer under controlled conditions;

in vivo oxyhemoglobin dissociation refers to these relationships as they occur physiologically in the body;

in indirect tension determinations the tensions in a small amount of blood are brought to equilibrium with a large amount of gas in a tonometer, the gas phase remaining virtually unchanged; and

in direct tension determinations the tension in a small gas bubble are brought to equilibrium with a relatively large volume of blood as drawn from the body; the blood phase remains virtually unchanged, and measurements are thus considered to indicate conditions as they occur in vivo. curve in vivo is to be found in the limited number of determinations which are plotted in the insert in Figure $1(2 a, 3)$. There is a sharp contrast between the scatter of their data and the more precise definition of a standard dissociation curve (Figure 52; 7b). These data, therefore, fail to establish the identity between oxyhemoglobin dissociation as it occurs in vivo and as it occurs in vitro. The recent development of a simpler and more accurate method for the direct determination of oxygen and carbon dioxide tensions in blood has provided the means for re-examining this important relationship.

This report describes the direct measurement of oxyhemoglobin dissociation in a variety of physiological states (rest, exercise, anoxia, and acapnia) for comparison with standard curves derived in vitro.

\section{METHODS}

\section{Experimental conditions}

At rest, blood samples were drawn under conditions which were designed to distribute points over the entire physiological range of the oxyhemoglobin dissociation curve. The oxygen tension of blood from the antecubital vein was reduced below $20 \mathrm{~mm}$. $\mathrm{Hg}$ by the combined effect of stasis and hand exercise. The range from 20 to $90 \mathrm{~mm}$. $\mathrm{Hg}$ was explored in venous samples drawn after varying degrees of vasodilatation had been accomplished by immersing the arm in hot water. Arterial samples covered the range from 90 to $100 \mathrm{~mm}$. $\mathrm{Hg}$.

During exercise, samples of arterial blood were obtained by means of an indwelling needle in the brachial artery. The subject either rode a bicycle ergometer or walked on an inclined treadmill, while the arm was supported in a sling. In some instances, anoxia was added to exercise by administering air diluted with $\mathrm{N}_{2}$.

Arterial samples were drawn under anoxic conditions produced by breathing air diluted with $\mathrm{N}_{2}$ at sea level, by exposure to simulated altitude in the decompression chamber, and by exposure to low concentrations of carbon monoxide. Details of the $\mathrm{CO}$ studies have been the subject of another report (6).

The effect of hyperventilation was studied by drawing 


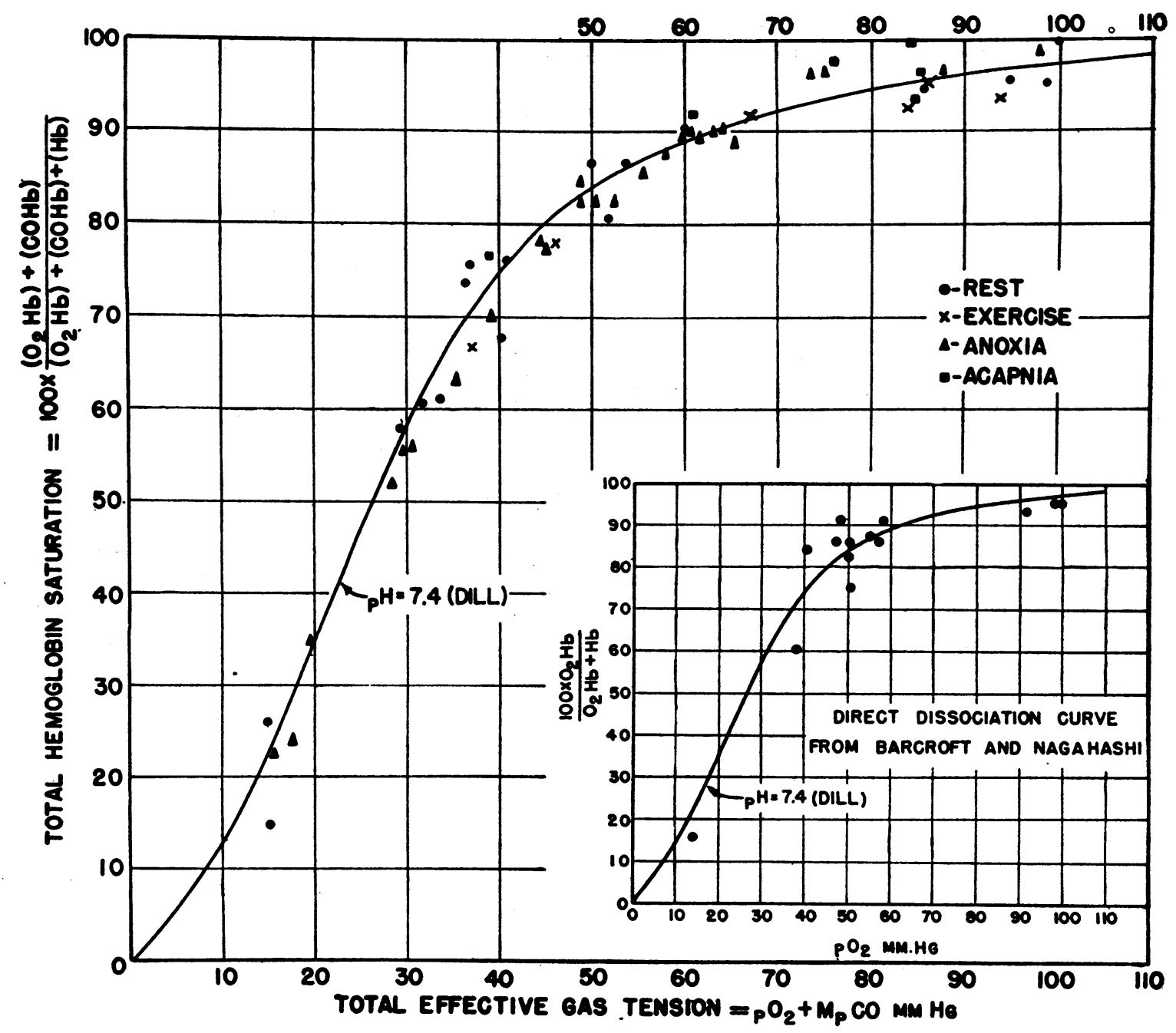

Fig. 1. Human Oxyhemoglobin Dissociation In Vivo

arterial blood while the subject breathed air diluted with $\mathrm{N}_{2}$ at sea level, and while he was exposed to simulated altitude in the decompression chamber. At sea level the subjects hyperventilated for 4 minutes at rates of $20 \pm 5$ liters per minute before the blood was drawn. The ventilation in the low pressure chamber experiments was of the same order.

\section{Analytical technics}

An anticoagulant and antiglycolytic solution was made up as follows: heparin solution (Lederle) $2 \mathrm{mgm}$. per ml., and sodium fluoride 4 per cent, in physiological saline. Three drops of solution were used for each $12 \mathrm{ml}$. blood sample, making the final concentration of fluoride in the blood approximately 0.05 per cent. Blood samples were drawn into chilled syringes in which the dead space had been eliminated with the heparin-fluoride solution and a few small drops of mercury to stir the sample. The 12 $\mathrm{ml}$. sample sufficed for performing all the analyses in duplicate. For arterial samples, an indwelling needle was introduced into the brachial artery in advance, and discomfort and uncertainty at the time of sampling were thus eliminated. The sample of blood was drawn directly into the prepared syringe which was then rotated vigorously, plugged with a round toothpick and immersed in ice water.

\section{Blood gases}

\section{1. $\mathrm{O}_{2}$ and $\mathrm{CO}$ content}

The combined microgasometric methods of Roughton and Scholander were used throughout (10).

\section{CO capacity (Total gas capacity)}

The determination of the total gas capacity of the hemoglobin was made by a gasometric method or a photometric method or both.

(a) Gasometric

One-half $\mathrm{ml}$. of blood was rotated for 3 minutes with $1.5 \mathrm{ml}$. of 95 per cent $\mathrm{CO}$ in nitrogen in a $2.0 \mathrm{ml}$. syringe 
which contained a small drop of mercury. The gas was then expelled and the blood stored prior to analysis without contact with a gas phase. Pilot experiments established the fact that this procedure completely saturated the hemoglobin with CO. Theoretical considerations and experimental analyses showed that a sample of blood treated in this way will contain 1.4 volumes per cent $\mathrm{CO}$ in physical solution. This amount is subtracted, therefore, from the total gas capacity of the blood to obtain the total gas capacity of the hemoglobin alone.

In blood which is completely free of $\mathrm{CO}$, oxyhemoglobin capacity equals total gas capacity. However, when blood contains appreciable quantities of $\mathrm{CO}$, the oxyhemoglobin capacity as usually determined is less than the total gas capacity of the hemoglobin by an amount approximately equal to the original $\mathrm{CO}$ content. Neglect of the quantity of hemoglobin combined with $\mathrm{CO}$ in subjects who smoke may introduce appreciable errors in determining total capacity ( 0.5 to 1.5 volumes per cent). A comparison of gas capacities performed on aliquots of the same sample of blood is presented below; it indicates that the CO capacity as determined is equivalent to the sum of the $\mathrm{O}_{2}$ capacity and the $C O$ content:

\begin{tabular}{|c|c|c|c|c|c|}
\hline & $\stackrel{(1)}{\text { content }}$ & $\begin{array}{c}(2) \\
\mathrm{O}_{2} \\
\text { capacity }\end{array}$ & $\begin{array}{c}(3) \\
1+2\end{array}$ & $\stackrel{(4)}{\text { Copacity }}$ & \\
\hline $\begin{array}{l}1 \\
1 a\end{array}$ & $\begin{array}{l}1.25 \\
1.35\end{array}$ & $\begin{array}{l}19.45 \\
19.35\end{array}$ & $\begin{array}{l}20.70 \\
20.70 \\
21.60\end{array}$ & $\begin{array}{l}20.80 \\
20.90 \\
21.80\end{array}$ & $\begin{array}{l}\text { (smoker) } \\
\text { (same blood after } \\
24 \text { hours in a re- } \\
\text { frigerator } 5^{\circ} \mathrm{C} . \text { ) } \\
\text { (non-smoker) }\end{array}$ \\
\hline
\end{tabular}

(b) Photometric

The photoelectric colorimeter of Andrews and Horecker (1) was used to estimate the total gas capacity of the hemoglobin. The reliability of this instrument is indicated by the following table which presents the comparative analyses performed on 11 consecutive samples of blood obtained during the present studies:

$\begin{array}{ccr}\text { Gasometric (CO) } & \begin{array}{c}\text { Total capacity } \\ \text { Photometric } \\ \text { solumes per cent }\end{array} & \Delta \\ 20.2 & 20.5 & +0.3 \\ 18.7 & 18.5 & -0.2 \\ 21.2 & 21.4 & +0.2 \\ 22.5 & 22.4 & -0.1 \\ 20.0 & 20.7 & +0.7 \\ 20.6 & 20.4 & -0.2 \\ 17.1 & 16.9 & -0.2 \\ 18.5 & 18.5 & 0.0 \\ 20.7 & 20.6 & -0.1 \\ 20.2 & 20.1 & -0.1 \\ 18.7 & 18.9 & +0.2 \\ & & 0.2\end{array}$

\section{Per cent saturation}

Total hemoglobin saturation refers to the ratio of the total gas content to the total gas capacity of the hemoglobin. In terms of per cent, this may be expressed as follows :

$$
100 \times \frac{\left(\mathrm{O}_{2} \mathrm{Hb}\right)+(\mathrm{COHb})}{\left(\mathrm{O}_{2} \mathrm{Hb}\right)+(\mathrm{COHb})+(\mathrm{Hb})} .
$$

4. $\mathrm{pO}_{2}$ and $\mathrm{pCO}_{2}$

The blood gas tensions determinations by the direct method of Riley, Proemmel and Franke were completed within 10 to 15 minutes after the sample was obtained (8).

5. $\mathrm{CO}_{2}$ content of whole blood- $\left(\mathrm{CO}_{2}\right)_{\mathrm{b}}$

The $\mathrm{CO}_{2}$ contents were determined by the manometric method of Van Slyke and Neill. The samples of blood which had been treated with $\mathrm{NaF}$ were maintained in ice until the analyses were begun and thus were at room temperature for only 15 minutes prior to analysis. Therefore, no correction for glycolysis was made.

\section{METHOD OF PLOTTING POINTS ON OXYHEMO- GLOBIN DISSOCIATION CURVE}

In the absence of $\mathrm{CO}$, points on the oxyhemoglobin dissociation curve may be plotted simply as oxygen tension against oxyhemoglobin saturation. Carbon monoxide, however, displaces the oxyhemoglobin dissociation curve to the left, so that a correction must be applied before comparison can be made with standard oxyhemoglobin curves. Since significant amounts of $\mathrm{CO}$ were present in many of the samples studied, the CO corrections were applied throughout.

The correction for $\mathrm{CO}$ is based upon Haldane's second "law": in blood exposed to oxygen at a partial pressure $\mathrm{pO}_{2}$ and to $\mathrm{CO}$ at a partial pressure $\mathrm{pCO}$, the total hemoglobin saturation is the same as it would be in the absence of $\mathrm{CO}$, if $\mathrm{pO}_{2}$ then equaled $\mathrm{pO}_{2}+\mathrm{MpCO}^{\circ}$ (total effective gas tension). The data required to plot total hemoglobin saturation against total gas tension are obtained by direct determinations with the exception of $\mathrm{MpCO}$, and this quantity can be calculated from the Haldane equation :

$\frac{\mathrm{MpCO}}{\mathrm{pO}_{2}}=\frac{\mathrm{CO} \text { content }}{\mathrm{O}_{2} \text { content }} ; \quad \mathrm{MpCO}=\mathrm{pO}_{2} \times \frac{\mathrm{CO} \text { content }}{\mathrm{O}_{2} \text { content }}$.

Data were corrected in this manner for the "Haldane effect" and were then compared directly to standard values for oxyhemoglobin dissociation in the absence of CO (see Table I and Figure 1).

pH.

Calculation of $\mathrm{pH}_{8}$ from $\mathrm{pCO}_{2}$ and $\left(\mathrm{CO}_{2}\right)_{b}$ (Henderson-Hasselbalch)

The graphic methods contained in the Syllabus of Methods of the Fatigue Laboratory were used (5).

1. Total $\mathrm{CO}_{2}$ of oxygenated blood

The difference in $\mathrm{CO}_{2}$ content between reduced $(r)$ and oxygenated (o) blood, (total $\left.\mathrm{CO}_{2}\right)_{2}-\left(\text { total } \mathrm{CO}_{2}\right)_{0}$, was estimated graphically (5) using total hemoglobin capacity as determined and an assumed $T_{40}$ of $47.5 \mathrm{vol}$ umes per cent. (The error resulting from this assumption is negligible in our group of normal subjects.)

- $M$ is the relative affinity constant of hemoglobin for CO compared to $\mathrm{O}_{2}$; it is approximately 210 in man. 
TABLE I

Blood gas data

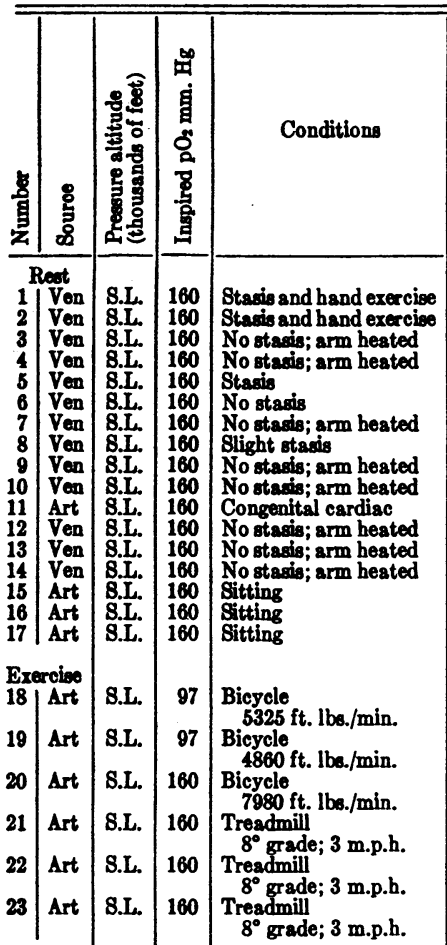

\begin{tabular}{|c|c|c|c|c|c|c|c|c|c|c|c|}
\hline \multirow{2}{*}{\multicolumn{2}{|c|}{ 臬 }} & \multirow{2}{*}{ 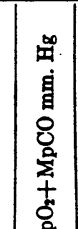 } & \multicolumn{3}{|c|}{$\mathrm{O}_{2}$} & \multicolumn{3}{|c|}{ CO } & \multicolumn{3}{|c|}{$\mathrm{O}_{2}+\mathrm{CO}$} \\
\hline & & & $\begin{array}{l}\dot{0} \\
\dot{0} \\
\dot{0} \\
\overrightarrow{\mathbf{g}} \\
\dot{8} \\
0\end{array}$ & 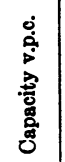 & 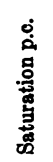 & 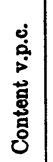 & 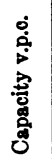 & 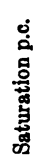 & 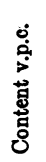 & 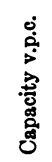 & 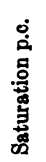 \\
\hline
\end{tabular}

\begin{tabular}{|c|c|c|c|c|}
\hline \multirow[b]{2}{*}{ 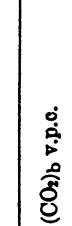 } & \multirow[b]{2}{*}{$\begin{array}{l}\stackrel{0}{0} \\
\stackrel{0}{0} \\
\stackrel{0}{0}\end{array}$} & \multirow[b]{2}{*}{ 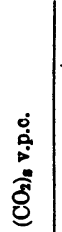 } & \multicolumn{2}{|c|}{$\mathrm{pH}$} \\
\hline & & & 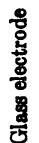 & 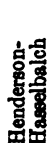 \\
\hline
\end{tabular}

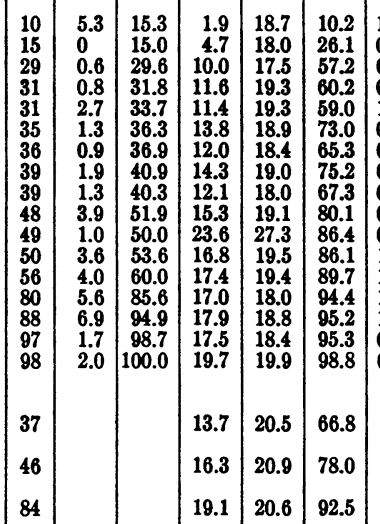

\begin{tabular}{l|l|l|l|l|l|l|l|l|l|l|l|l|l|l|l|l|l}
67 & 2.1 & 69.1 & 15.6 & 17.0 & 91.7 & 0.5 & 17.5 & 2.9 & 16.1 & 17.5 & 92.0 & 48 & 50.2 & 46.5 & 58.3 & 7.340 & 7.35
\end{tabular} \begin{tabular}{|l|l|l|l|l|l|l|l|l|l|l|l|l|l|l|l|l|l|}
86 & 1.4 & 87.4 & 18.1 & 19.0 & 95.2 & 0.3 & 19.3 & 1.5 & 18.4 & 19.3 & 95.3 & 42 & 49.9 & 48.8 & 59.5 & 7.400 & 7.41
\end{tabular} \begin{tabular}{l|l|l|l|l|l|l|l|l|l|l|l|l|l|l|l|l|l}
90 & 3.9 & 93.9 & 20.5 & 22.0 & 93.2 & 0.9 & 22.9 & 3.1 & 21.4 & 22.9 & 93.4 & 41 & 44.8 & 44.0 & 54.9 & 7.340 & 7.38
\end{tabular} $\begin{array}{llllllllllllllllllll}61 & 4.2 & 65.2 & 17.6 & 20.0 & 88.0 & 1.2 & 21.2 & 5.7 & 18.8 & 21.2 & 88.7 & 36 & 48.6 & 49.6 & 59.0 & 7.420 & 7.48\end{array}$

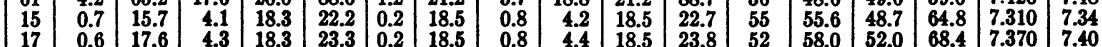

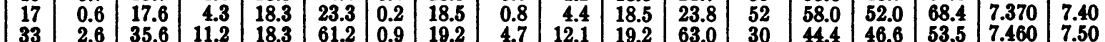

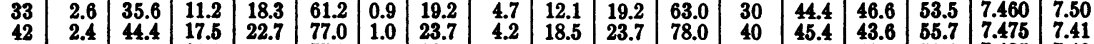
\begin{tabular}{ll|l|l|l|l|l|l|l|l|l|l|l|l|l|l|l|l|l}
44 & 0.9 & 44.9 & 14.1 & 18.2 & 77.5 & 0.3 & 18.5 & 1.6 & 14.4 & 18.5 & 77.9 & 41 & 50.0 & 48.4 & 59.1 & 7.425 & 7.42
\end{tabular} \begin{tabular}{l|l|l|l|l|l|l|l|l|l|l|l|l|l|l|l|l|l|l}
47 & 3.2 & 50.2 & 14.7 & 18.0 & 81.6 & 1.0 & 19.0 & 5.3 & 15.7 & 19.0 & 82.6 & 35 & 47.7 & 51.0 & 58.0 & 7.480 & 7.48 \\
54 & 13 & 55.3 & 16.3 & 19.2 & 85 & 0.4 & 19.6 & 2.0 & 16.7 & 19.6 & 85.2 & 35 & 49.3 & 50.5 & 59.3 & 7.465 & 7.49
\end{tabular}

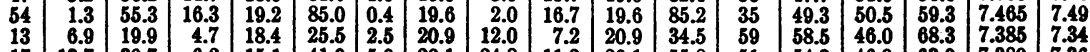
\begin{tabular}{l|l|l|l|l|l|l|l|l|l|l|l|l|l|l|l|l|l|l|l|}
17 & 13.7 & 30.7 & 6.2 & 15.1 & 41.0 & 5.0 & 20.1 & 24.8 & 11.2 & 20.1 & 55.8 & 51 & 54.3 & 46.9 & 63.9 & 7.380 & 7.36
\end{tabular} \begin{tabular}{|c|c|c|c|c|c|c|c|c|c|c|c|c|c|c|c|c|c|c|}
20 & 9.7 & 29.7 & 7.0 & 15.4 & 45.4 & 3.4 & 18.8 & 18.1 & 11.4 & 18.8 & 55.3 & 57 & 57.9 & 47.7 & 67.6 & 7.370 & 7.35 \\
\hline
\end{tabular} \begin{tabular}{|r|r|r|r|r|r|r|r|r|r|r|r|r|r|r|r|r|r|}
21 & 7.3 & 28.3 & 8.1 & 18.1 & 44.7 & 2.8 & 20.9 & 13.4 & 10.9 & 20.9 & 52.1 & 49 & 58.5 & 50.7 & 69.7 & 7.420 & 7.42
\end{tabular}

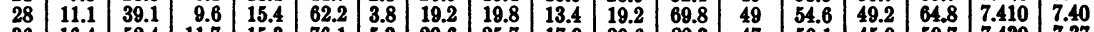

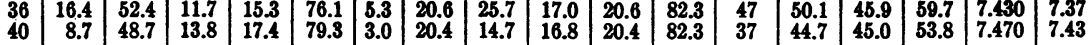
\begin{tabular}{|l|l|l|l|l|l|l|l|l|l|l|l|l|l|l|l|l|l}
40 & 8.7 & 48.7 & 13.7 & 16.7 & 82.0 & 3.0 & 19.7 & 15.2 & 16.7 & 19.7 & 84.7 & 29 & 44.0 & 48.5 & 53.9 & 7.510 & 7.53
\end{tabular} \begin{tabular}{|l|l|l|l|l|l|l|l|l|l|l|l|l|l|l|l|l|l|l|}
54 & 5.7 & 59.7 & 15.1 & 17.0 & 88.8 & 1.6 & 18.6 & 8.6 & 16.7 & 18.6 & 89.7 & 37 & 46.7 & 47.0 & 55.6 & 7.415 & 7.44
\end{tabular} \begin{tabular}{|l|l|l|l|l|l|l|l|l|l|l|l|l|l|l|l|l|l|l|}
54 & 5.7 & 59.7 & 15.2 & 17.0 & 89.4 & 1.6 & 18.6 & 8.6 & 16.8 & 18.6 & 90.3 & 40 & 47.1 & 46.5 & 55.3 & 7.415 & 7.41
\end{tabular} \begin{tabular}{|l|l|l|l|l|l|l|l|l|l|l|l|l|l|l|l|l|l|l}
54 & 4.8 & 58.8 & 16.2 & 18.6 & 87.2 & 1.4 & 20.1 & 7.2 & 17.7 & 20.1 & 87.8 & 36 & 46.4 & 47.5 & 56.1 & 7.440 & 7.45
\end{tabular} \begin{tabular}{|l|l|l|l|l|l|l|l|l|l|l|l|l|l|l|l|l|l|l|}
58 & 5.1 & 63.1 & 16.3 & 18.3 & 89.0 & 1.4 & 19.7 & 7.3 & 17.8 & 19.7 & 90.0 & 33 & 46.6 & 49.2 & 56.9 & 7.450 & 7.49
\end{tabular} \begin{tabular}{|l|l|l|l|l|l|l|l|l|l|l|l|l|l|l|l|l|l}
56 & 5.1 & 61.1 & 16.4 & 18.5 & 88.6 & 1.5 & 20.0 & 7.5 & 17.9 & 20.0 & 89.5 & 33 & 46.8 & 49.5 & 57.0 & 7.485 & 7.50
\end{tabular} \begin{tabular}{|l|l|l|l|l|l|l|l|l|l|l|l|l|l|l|l|l|l}
59 & 5.3 & 64.3 & 16.5 & 18.5 & 89.2 & 1.5 & 20.0 & 7.5 & 18.0 & 20.0 & 90.0 & 36 & 46.9 & 48.2 & 57.1 & 7.470 & 7.47
\end{tabular} \begin{tabular}{|l|l|l|l|l|l|l|l|l|l|l|l|l|l|l|l|l|l|}
63 & 10.6 & 73.6 & 14.3 & 14.9 & 96.0 & 2.4 & 17.3 & 13.9 & 16.7 & 17.3 & 96.5 & 32 & 47.2 & 47.0 & 56.3 & 7.440 & 7.50
\end{tabular} \begin{tabular}{|l|l|l|l|l|l|l|l|l|l|l|l|l|l|l|l|l|l|}
64 & 11.0 & 75.0 & 14.3 & 14.9 & 96.2 & 2.5 & 17.3 & 14.2 & 16.8 & 17.3 & 96.8 & 35 & 47.0 & 48.9 & 55.8 & 7.430 & 7.46
\end{tabular} \begin{tabular}{lllll|l|l|l|l|l|l|l|l|l|l|l|l|l|l|l}
66 & 21.4 & 87.4 & 14.2 & 14.9 & 95.7 & 4.6 & 19.5 & 23.6 & 18.8 & 19.5 & 96.7 & 38 & 48.1 & 49.0 & 58.1 & 7.405 & 7.45
\end{tabular} \begin{tabular}{ll|l|l|l|l|l|l|l|l|l|l|l|l|l|l|l|l}
69 & 21.8 & 90.8 & 14.5 & 14.7 & 98.5 & 4.6 & 19.3 & 23.8 & 19.1 & 19.3 & 98.9 & 36 & 48.3 & 49.9 & 58.6 & 7.415 & 7.47
\end{tabular} \begin{tabular}{lllllllllllll|l|l|l|l|l|l|}
37 & 1.8 & 38.8 & 14.0 & 18.5 & 75.6 & 0.7 & 19.2 & 3.7 & 14.7 & 19.2 & 76.5 & 38 & 50.6 & 50.0 & 60.8 & 7.450 & 7.47
\end{tabular} \begin{tabular}{|l|l|l|l|l|l|l|l|l|l|l|l|l|l|l|l|l|l|l|l}
59 & 1.9 & 60.9 & 15.2 & 16.6 & 91.5 & 0.5 & 17.1 & 2.9 & 15.7 & 17.1 & 91.7 & “25” & 42.8 & 49.0 & 51.5 & 7.560 & 7.57
\end{tabular} \begin{tabular}{ll|l|l|l|l|l|l|l|l|l|l|l|l|l|l|l|l}
72 & 4.3 & 76.3 & 18.5 & 18.9 & 97.9 & 1.1 & 20.0 & 5.5 & 19.6 & 20.0 & 97.9 & 21 & 37.4 & 47.6 & 46.7 & 7.565 & 7.60
\end{tabular} \begin{tabular}{l|l|l|l|l|l|l|l|l|l|l|l|l|l|l|l|l|l}
80 & 4.3 & 84.3 & 20.6 & 22.2 & 92.8 & 1.1 & 23.3 & 4.7 & 21.7 & 23.3 & 93.1 & 24 & 37.7 & 46.8 & 48.9 & 7.605 & 7.57
\end{tabular} \begin{tabular}{|l|l|l|l|l|l|l|l|l|l|l|l|l|l|l|l|l|l}
82 & 3.6 & 85.6 & 20.5 & 21.6 & 95.0 & 0.9 & 22.5 & 4.0 & 21.6 & 22.5 & 25.8 & 23 & 38.8 & 47.9 & 49.5 & 7.570 & 7.59
\end{tabular}

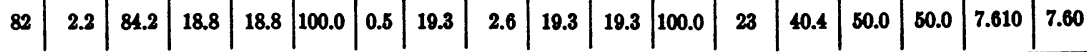


This difference was multiplied by the per cent unsaturation of the blood, and the product was subtracted from $\left(\mathrm{CO}_{2}\right)_{\text {b }}$ to derive (total $\left.\mathrm{CO}_{2}\right)_{\text {o }}$.

\section{2. $T_{\infty}$}

The total $\mathrm{CO}_{2}$ of oxygenated blood at $\mathrm{pCO}_{2}=40\left(\mathrm{~T}_{\mathrm{w}}\right)$ was read from the line chart (5) using determined values for $\mathrm{pCO}_{3}$ and total hemoglobin capacity, and the calculated value for (total $\mathrm{CO}_{2}$ ) o.

3. Total $\mathrm{CO}_{2}$ content of serum- $\left(\mathrm{CO}_{2}\right)_{8}$

$\left(\mathrm{CO}_{2}\right)=-\left(\mathrm{CO}_{2}\right)_{1}$ was estimated graphically (5) using total hemoglobin capacity and $T_{40}$. This amount was

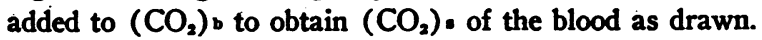

4. $p H$.

pH. was estimated from the line chart representation of the Henderson-Hasselbalch equation,

$$
\mathrm{pH}_{2}=6.10+\log \frac{\left(\mathrm{HCO}_{2}\right)}{\left(\mathrm{H}_{2} \mathrm{CO}_{2}\right)},
$$

using $\mathrm{pCO}_{2}$ as determined and $\left(\mathrm{CO}_{2}\right)$. as calculated in 3 above (Figure 87, $7 \mathrm{~b}$ ). The correspondence between the pH. calculated by the Henderson-Hasselbalch equation

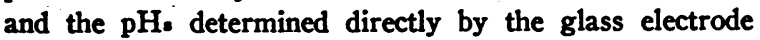
served as a check of the accuracy of the several related determinations.

\section{Determination of $\mathrm{pH}_{\mathrm{s}}$ (glass electrode)}

The $\mathrm{pH}$. was determined on samples of whole blood by means of a MacInnes and Belcher type of glass electrode (Cambridge Instrument $C_{0}$.). The sensitivity of this instrument is of the order of $0.005 \mathrm{pH}$ units and the reproducibility of duplicate determinations is $0.01 \mathrm{pH}$ units. The standard instrument was modified to permit the measurement of the $\mathrm{pH}$. at $37^{\circ} \mathrm{C}$. by mounting the glass electrode assembly, the internal silver-silver chloride electrode and the calomel reference electrode in a shielded box which was placed in a thermostatically controlled warm air bath. All solutions introduced into the electrode were maintained at $37^{\circ} \mathrm{C}$. in the warm air bath so that thermal gradient potentials were reduced to insignificance. The electrode potentials were led to the amplifier unit by coaxial cables which eliminated any detectable interference.

The solution of potassium chloride used as a salt bridge was saturated at room temperature $\left(23^{\circ} \mathrm{C}\right.$.), and the supernatant solution was decanted from the excess salt before storage in the warm air bath at $37^{\circ} \mathrm{C}$. with provision to prevent further concentration of the solution through evaporation.

The null-point potentiometer circuit was standardized before each set of determinations with a $0.05 \mathrm{M}$ potassium acid phthalate solution. At this temperature, the presently accepted value for the $\mathrm{pH}$ is 4.026 .7 The circuit then was calibrated with freshly mixed Sørensen phosphate buffers of the following composition and $\mathrm{pH}$ at $37^{\circ} \mathrm{C}$ :

' Dr. W. J. Hamer, of the National Bureau of Standards, very kindly furnished the calculated $\mathrm{pH}$ of the solutions used at $37^{\circ} \mathrm{C}$.

$\begin{array}{ccc}\text { NasHPO } \mathrm{ml} . & \mathrm{KH}_{2} \mathrm{PO}_{\mathbf{4}} \mathbf{m l} . & \mathrm{pH} \\ 7 & 3 & 7.170 \\ 8 & 2 & 7.400 \\ 10 & 2 & 7.490 \\ 9 & 1 & 7.750\end{array}$

The blood, drawn into an iced syringe, was iced until 5 minutes before analysis when it was rotated in a water bath at $37^{\circ} \mathrm{C}$. The sample of blood was then transferred to the glass electrode capillary in aliquots of $0.5 \mathrm{ml}$. and the $\mathrm{pH}$. determined in triplicate. Repeated observations have established the fact that with this handling of the samples, there occurred no detectable rise in $\mathrm{pH}$. owing to escape of $\mathrm{CO}_{2}$.

In order to determine whether analyses by the technics described above could be compared to the results obtained by standard technics (5), the following control experiments were performed. Six samples of blood were equilibrated in large tonometers at $37^{\circ} \mathrm{C}$. with suitable mixtures of $\mathrm{O}_{2}, \mathrm{CO}_{2}$, and $\mathrm{N}_{2}$. The gas phase was analyzed by the Haldane technic to determine the gas $\mathrm{pO}_{2}$; the blood was analyzed by the methods used in this study for $\mathrm{pO}_{2}, \mathrm{pH}$, and oxyhemoglobin saturation. The following table presents the results:

\begin{tabular}{|c|c|c|c|c|}
\hline \multicolumn{2}{|c|}{$\mathrm{pO}_{2}$} & \multirow{2}{*}{$\mathrm{pH}_{\mathbf{8}}$} & \multirow{2}{*}{$\underset{\text { saturation }}{\mathrm{O}_{2} \mathrm{Hgb}}$} & \multirow{2}{*}{$\begin{array}{l}\text { Deviation from } \\
\text { standard curve }\end{array}$} \\
\hline Gas & Blood & & & \\
\hline $\begin{array}{l}22^{m} \\
51 \\
58 \\
76 \\
76 \\
87\end{array}$ & $\begin{array}{l}\boldsymbol{H}_{\mathbf{g}} \\
20 \\
51 \\
56 \\
75 \\
73 \\
88\end{array}$ & $\begin{array}{l}7.445 \\
7.385 \\
7.440 \\
7.420 \\
7.620 \\
7.405\end{array}$ & $\begin{array}{c}\text { per cent } \\
38.4 \\
87.7 \\
89.8 \\
93.0 \\
93.8 \\
91.7\end{array}$ & $\begin{array}{c}\text { per cent } \\
-4.0 \\
+3.0 \\
+0.5 \\
-0.5 \\
-2.5 \\
-3.5\end{array}$ \\
\hline
\end{tabular}

These data demonstrate (1) the good correspondence between $\mathrm{pO}_{2}$ values determined from the gas phase and $\mathrm{pO}_{2}$ values determined by direct analysis of the blood and (2) that in vitro oxyhemoglobin dissociation is the same whether determined by standard technics or by the modifications described above.

\section{RESULTS}

The results of analyses of 55 blood samples are summarized in Table I and Figure 1. The 11 subjects were, with the exception of 1 subject with congenital heart disease, in good health. Three men were studied intensively; together they furnished 42 of the 55 samples.

\section{DISCUSSION}

In comparing the tension-saturation points determined by direct means with the standard oxyhemoglobin dissociation curve, the limits of accuracy of the experimental methods must be considered. The accuracy of the tension method 
is $\pm 3 \mathrm{~mm} . \mathrm{Hg}$ and that of the saturation method is \pm 1.5 per cent. The scatter of the experimental points about the standard curves is, in most instances, within the limits of accuracy of the experimental procedures (see Figure 1).

Since the position of the standard curve varies with $\mathrm{pH}_{\mathrm{s}}$, each individual point in the figure should be compared to a curve which has been established at the $\mathrm{pH}_{\mathrm{s}}$ of the given sample of blood. Actually 7.4 approximates the average $\mathrm{pH}_{\text {s }}$ of our data, and displacement away from this curve due to difference in $\mathrm{pH}_{\mathbf{8}}$ is in most cases small. In accord with the Bohr effect, the largest discrepancies occur in the hyperventilation experiments. Approximate corrections can be made by reference to the determined $\mathrm{pH}_{\mathrm{s}}$ values listed in the table.

If significant variations between individual oxyhemoglobin dissociation curves do exist, they are too small to be detected by the technics employed in this study. Apparently oxyhemoglobin dissociation remains extremely constant under given conditions within a given species. Certainly, in the data recorded here there is no evidence of variations in oxyhemoglobin dissociation characteristics in response to physiological stresses such as have been imposed in these experiments.

The question which prompted the study reported here has been answered in terms of presently available technics. The standard oxyhemoglobin dissociation curves which have been derived from equilibria reached in the tonometer describe accurately the tension-saturation relations as they occur in vivo, not only at rest but under a variety of moderate physiological stresses. The prediction of oxygen tension from a determined saturation may be made with confidence, at least at tensions less than $80 \mathrm{~mm}$. Hg. At oxygen tensions above $80 \mathrm{~mm}$. $\mathrm{Hg}$, the difficulties and errors which have been emphasized by others render invalid the indirect estimation of $\mathrm{pO}_{2}(9)$.

\section{SUMMARY}

1. The purpose of this study was to ascertain whether the standard oxyhemoglobin dissociation curves, derived from indirect determinations, describe with accuracy oxyhemoglobin dissociation as it occurs in vivo.

2. Data on the dissociation of oxyhemoglobin and on acid-base balance were obtained by direct methods in man in a variety of physiological states : rest, exercise, anoxia (anoxic and carbon monoxide), and acapnia.

3. The standard oxyhemoglobin dissociation curves were found to describe conditions as they exist in vivo.

\section{BIBLIOGRAPHY}

1. Andrews, H. L., and Horecker, B. L., A simplified photoelectric colorimeter for blood analysis. Rev. Sci. Instr., 1945, 16, 148.

2. Barcroft, J., The Respiratory Function of the Blood. (a) I. Lessons From High Altitude. Cambridge University Press, 1925; (b) II. Hemoglobin. Cambridge University Press, 1928.

3. Barcroft, J., and Nagahashi, M., The direct measurement of the partial pressure of oxygen in human blood. J. Physiol., 1921, 55, 339.

4. Henderson, L. J., Blood. A Study in General Physiology. Yale University Press, 1928.

5. Horvath, S. M., Consolazio, W. V., and Dill, D. B., Syllabus of Methods of the Fatigue Laboratory. Graduate School of Business Administration, Harvard University.

6. Lilienthal, J. L., Jr., Riley, R. L., Proemmel, D. D., and Franke, R. E., The relationships between carbon monoxide, oxygen, and hemoglobin in the blood of man at altitude. Amer. J. Physiol., 1946, 145, 351.

7. Peters, J. P., and Van Slyke, D. D., Quantitative Clinical Chemistry. (a) I. Interpretations; (b) II. Methods. Williams and Wilkins, Baltimore, 1932.

8. Riley, R. L., Proemmel, D. D., and Franke, R. E., A direct method for determination of oxygen and carbon dioxide tensions in blood. J. Biol. Chem., 1945, 161, 621.

9. Roughton, F. J. W., Darling, R. C., and Root, W. S., Factors affecting the determination of oxygen capacity, content, and pressure in human arterial blood. Amer. J. Physiol., 1944, 142, 708.

10. Roughton, F. J. W., and Scholander, P. F., Micro gasometric estimation of the blood gases. I. Oxygen, II. Carbon monoxide. J. Biol. Chem., 1943, 148,541 and 551. 